\title{
Tek Merkezli Endoskopik Retrograt Kolanjiyopankreatografi Deneyimlerimiz
}

\author{
Our Experience in Single Center Endoscopic Retrograde \\ Cholangiopancreatography
}

\author{
Esat Taylan UĞURLU ${ }^{1}$ (D), Mehmet TERCAN ${ }^{2}$ (D)
}

\begin{abstract}
${ }^{1}$ Sağlık Bilimleri Üniversitesi Şanlıurfa Mehmet Akif İnan Eğitim ve Araştırma Hastanesi, Genel Cerrahi Kliniği, Şanlıurfa, TÜRKiYE ${ }^{2}$ Sağlık Bilimleri Üniversitesi Şanlıurfa Mehmet Akif İnan Eğitim ve Araştırma Hastanesi, Anesteziyoloji ve Reanimasyon Kliniği Şanlıurfa, Türkiye
\end{abstract}

Öz.

Amaç: Endoskopik retrograd kolanjiopankreatografi (ERCP), safra yolu ve pankreasın benign ve malign patolojilerinin tanı ve tedavisinde etkin bir biçimde kullanılmaktadır. ERCP bilgi, beceri ve pratik gerektiren kompleks bir uygulamadır. Diğer endoskopik uygulamalardan farklı teknik ve ekipmanın kullanımı ve daha fazla komplikasyon görülmesiyle ayrılır.

Bu çalışmadaki amacımız bir genel cerrahi ERCP ünitesinin 19 aylık deneyimini paylaşmaktır.

Materyal ve Metod: Bu çalışmada15 Mayıs 2019-31Aralık 2020 tarihleri arasında klinik, medikal ve radyolojik verilerde kolestaz, obstruktif kolanjit/pankreatit veya safra kaçağı tanısı konulan ve ERCP işlemi yapılan 513 hastanın verileri retrospektif olarak değerlendirmiştir.

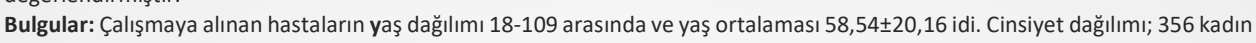
$(\% 69,4), 157$ erkek $(\% 30,6)$ şeklinde idi. En sık ERCP endikasyonlarımız; safra yolu tıkanıklığına bağlı kolestaz, tıkanma ikteri, akut pankreatit veya kolanjit idi. Bu hastaların 452 si koledok taşı, 15'i pankreas başı tümörü, 11'i koledok tümörü ve 10'u papilla tümörü idi.10 hasta Oddi Sfinkter Disfonksiyonu( ODS) nedeniyle işleme alındı. Safra yolu tıkanılığı ile gelen 499 hastanın $63^{\prime} u ̈ ~$ akut biliyer pankreatit, 38 i akut kolanjit tanılarıyla yatırıımıştı. Geri kalan 14 hastanın 7'sine karaciğer kist hidatik ameliyatı sonrası, 3'üne safra kesesi ameliyatı sonrası safra kaçağı, 4' üne safra kesesi ameliyatı sonrası safra yolu stenozu tanısı ile ERCP yapıldı. İşlem süresi 20 dakikayla 90 dakika arasında değişti (ortalama işlem süresi $37 \mathrm{dk}$ ). Hastaların ERCP sonrası, 56'sında tedavi gerektirmeyen amilazemi, 24 'ünde ortalama 3 günlük medikal tedaviyle gerileyen pankreatit, 5'inde kan transfüzyonu gerektirmeyen ve adrenalin enjeksiyonu ve balon baskısıyla kontrol edilebilen kanama gelişti. Bir hastada taş ekstraksiyonu sırasında basket ve taş papillada sıkışmıștı. Operatif mortalite olmadı.

Sonuç: Safra yollarındaki kaçaklar ve fistüller en iyi ERCP ile gösterilir ve endoskopik olarak tedavi edilir. ERCP etkin olduğu kadar bünyesinde perforasyon, sepsis ve mortalite gibi çok ciddi komplikasyonları barındırdığından endoskopistin uygulamanın endikasyonunu doğru belirlemesi, potansiyel komplikasyonlarını bilmesi ve oluşan komplikasyonları erken bir şekilde tanıması ve tedavisini yönetmesi, komplikasyon yaratacak gereksiz uygulamalardan mümkün olduğunca kaçınması gerektiği kanaatindeyiz.

Anahtar Kelimeler: ERCP, Endoskopik Sfinkteretomi, Kolanjit, Pankreatit

Abstract

Background: Endoscopic retrograde cholangiopancreatography (ERCP) is used in the diagnosis and treatment of benign and malignant pathologies of the biliary tract and pancreas. ERCP is a complex application that requires knowledge, skills and practice. It differs from other endoscopic applications with the use of different techniques and equipment and possibility of more complications.

Our aim in this study is to share the 19-month experience of a general surgery of ERCP unit.

Materials and Methods: This study retrospectively evaluated 513 patients that were diagnosed with cholestasis, obstructive cholangitis / pancreatitis or bile leakage between May 15, 2019 and December 31, 2020 and were applied ERCP in clinical, medical and radiological data.

Results: The age distribution of the participants was between 18-109 and the mean age was $58.54 \pm 20.16$ years. The gender distribution was 356 women (69.4\%), 157 men (30.6\%). The most common diagnoses were cholestasis, obstructive icterus, acute pancreatitis or cholangitis due to bile duct obstruction. Among the patients, 452 were common bile duct stones, 15 were pancreatic head tumors, 11 were common bile duct tumors, and 10 were papillae tumors. 10 patients were processed for Oddi Sphincter Dysfunction. Among 499 patients who came with bile duct obstruction, 63 were hospitalized with the diagnosis of acute biliary pancreatitis and 38 with the diagnosis of acute cholangitis. The procedure time varied from 20 minutes to 90 minutes (average processing time 37 minutes). After ERCP, 56 of the patients developed amylazemia that did not require treatment, 24 patients developed pancreatitis, which regressed with 3 days of medical treatment and 5 patients bleeding that did not require blood transfusion and could be controlled by adrenaline injection and balloon pressure. During a stone extraction, the basket and stone were trapped in a patient. There was no operative mortality.

Conclusion: Leaks and fistulas in the bile ducts are best shown with ERCP and treated endoscopically. We believe that endoscopist should determine the indication of the ERCP application correctly, know the potential complications, manage the treatment early, avoid unnecessary and complicated applications as much as possible since endoscopy includes very serious complications such as perforation, sepsis as much as it is effective.

Key Words: ERCP, Endoscopic Sphincterotomy, Cholangitis, Pancreatitis
Sorumlu Yazar/Corresponding Author

Dr. Esat Taylan UĞURLU

Sağlık Bilimleri Üniversitesi Şanlıurfa Mehmet Akif İnan Eğitim ve Araştırma Hastanesi, Genel Cerrahi kliniği, Esentepe Mah. Ertuğrul Cad. posta kodu 63300 Haliliye/ Şanlıurfa TÜRKIYE

E-mail: doktoramca_1971@hotmail.com

Geliş tarihi / Received: 03.04.2021

Kabul tarihi / Accepted: 15.06.2021

DOI: $10.35440 /$ hutfd.908948 


\section{Giriş}

İlk defa 1974 yılında gerçekleştirilen ERCP (Endoskopik Retrograd Kolanjiopankreatografi) işlemi; yan görüşlü bir endoskop aracılığı ile papilla vaterinin kanüle edilerek, safra yolları ve pankreas kanalının kontrast madde verilerek radyolojik olarak görüntülenmesi işlemidir. Safra yollarından kaçaklar, darlıklar ve fistüller en iyi ERCP ile gösterilir ve endoskopik olarak tedavi edilir. (1). ERCP hepatobiliyer ve pankreas hastalıklarının tanı ve tedavisinde yararlı bir tekniktir. Günümüzde gelişen teknoloji ile birlikte terapötik amaçla daha çok kullanılmaktadır. Ana safra kanalındaki taşları tespit etmede ERCP'nin yüksek sensitivite ve spesifitesi vardır. Pankreatikobiliyer kanalda ve ampullada yer alan kitlelerden biopsi alınabilir (2). ERCP etkin bir tanı ve tedavi yöntemi olduğu kadar ciddi komplikasyonları da olan bir işlemdir. Çalışmalarda \%10'a varan morbidite ve $\% 1^{\prime}$ e varan mortalite oranları bildirilmektedir (3). ERCP'nin invaziv bir girişim olması potansiyel komplikasyonlara ait riskleri de birlikte getirmektedir. Son yıllarda multidedektör bilgisayarlı tomografik kolanjiografi (MDBTkolanjiografi), magnetik rezonans kolanjiopankreatografi (MRCP) ve endoskopik ultrasonografi (EUS) gibi görüntüleme tekniklerinin gelişmesi ile tanısal ERCP giderek daha az kullanılır olmuştur (4).

Bu calısmanın amacı, ERCP vakalarımızın endikasyonlarını, teşhis araçlarımızı, görüntüleme yöntemleriyle işlem esnasındaki teşhis uyumunu, ERCP sonrası komplikasyonların sıklığını belirlemek, her bir komplikasyon için bazı risk faktorlerini ve belirleyicileri tanımlamak, çalışmaya alınan ERCP vakalarına ait sonuçları sunmaktır.

\section{Materyal ve Metod}

Çalışmanın etik kurul onamı Harran Üniversitesi klinik araştırmalar etik kurulundan (15.03.2021-HRU 21.06.10) alınmıştır. Bu çalışmaya Şanlıurfa Mehmet Akif Inan Eğitim Araştırma Hastanesi Genel Cerrahi ERCP Ünitesinde 15 Mayıs 2020 -31 Aralık 2020 tarihleri arasında ERCP yapılan 513 hasta alınmış olup yaş, cinsiyet, ERCP endikasyonu, yapılan işlemler, başarı durumu, ERCP sonrası komplikasyonlar, MRCP raporları ile ERCP işlemindeki tanıların karşılaştırılması retrospektif olarak değerlendirilmiştir. Bu çalışmada elde edilen veriler hastanemiz merkezi veri tabanı ve hasta dosyalarından alınmıştır. İşlem öncesi tüm hastalardan preoperatif anesteziyoloji konsültasyonu yapılarak aydınlatılmış onam formu alındı. ERCP işlemi için endikasyon; hastaların klinik bulguları, hemogram-biyokimya sonuçları, görüntüleme yöntemlerinden batın ultrasonografisi, bilgisayarlı tomografi (BT) ve MRCP raporlarına göre ile konuldu. ERCP işlemi; genel anestezi altında monitorize şekilde yapıldı. Cihazlarımız Olympus Exera II CV-180 ve Fujifilm Processor VP-3500HD idi. Her hastaya Sefaperazon + Sulbaktam (Sulperazon) ve metronidazol 1gr yapıldı. İşlem sonrası her hasta en az 1 gün takip edildi. Komplikasyonları olan hastalar klinik durumları düzelene kadar serviste takip edildi.
İstatistiksel analizler için 'SPSS for Windows Versiyon 20' bilgisayar programı kullanıldı. Kategorik değişkenler sayı ve yüzde ile ifade edildi.

\section{Bulgular}

Toplam 513 hastaya ERCP işlemi yapıldı. Yaş aralığı 18$109 /$ yı olup, bu hastaların 356'sı kadın (\%69,3), 157'si erkek $(\% 30,7)$ idi. Hastaların 499 u safra yolu tıkanıklığına bağlı kolestaz, tıkanma ikteri, akut pankreatit veya kolanjit tanısıyla kliniğe kabul edildi. Bu hastaların 452'sine koledok taşı tanısıyla ERCP yapıldı. Koledok taşı olan hastaların tamamına endoskopik sfinkterotomi (ES) yapıldı. Koledok taşı olan hastaların 435'ine balon ve basket kateter ile taş ekstraksiyonu yapılırken çıkamayacak kadar büyük taşları olan 17 hastaya koledok stentlemesi yapıldı. Plastik stent konulan hastaya 3 ay sonra tekrar ERCP yapıldı ve stentleri çıkarılıp taş ekstraksiyon yapıldı. Safra yolu tıkanmasıyla gelen hastaların 15'i pankreas başı tümörü idi. Bu hastaların tamamına ES yapıldı ve koledoğa plastik stent yerleştirildi (Şekil 1a, 1b, 1c). 11'ine koledok tümörü tanısı konulmuştu.

Bu hastaların 1'i proksimal koledok tümörü idi ve bu hastaya ana hepatik kanalın başlangıç kısmına kadar uzanan stent yerleştirildi (Şekil 2a, 2b). Koledok tümörü tanısyla ERCP yapılan diğer 10 hasta distal koledok tümörü idi. Bu hastalara da ES sonrası koledok stentlemesi yapıldı. Safra yolu tıkanıklığı olan 10 hastaya papilla tümörü tanısıyla ERCP yapılmıştı. (Şekil 3). Papilla tümörü olduğu düşünülen hastalara işlem esnasında papil biyopsisi yapıldı. Bu hastaların 6'sının patoloji sonucu Adenokarsinom olarak raporlandı. Biyopsi yapılan 4 hastaya yetersiz materyal nedeniyle patolojik tanı konulamadı. 10 hastaya Oddi Sfinkter Disfonksiyonu (ODS) tanısıyla ERCP yapıldı. Teknik şartlar nedeniyle monometri uygulanamadıysa da işlem öncesi bu hastalarda biyokimyasal anormalliklerin yanı sıra klinik semptomlar da vardı. MRCP görüntülemeleri koledok distal uçta daralama ve koledokta genişleme şeklinde raporlanmıştı. ODS nedeniyle ERCP yapılan hastalarda işlem sonrası klinik bulgularda ve laboratuvar değerlerinde düzelme olmuştu. ERCP yapılan hastalara 7'si karaciğer kist hidatik ameliyatı sonrası, 3'ü safra kesesi ameliyatı sonrası safra kaçağı, 4' ü safra kesesi ameliyatı sonrası safra yolu stenozu tanısı konulmuştu. Karaciğer kist hidatik ameliyatı sonrası safra kaçağı olan hastalara öncelikle medikal tedavi yapılmıştı. Safra kaçağı yüksek debili olduğundan bu hastalara ERCP yapıldı. ES sonrası koledoğa plastik stent yerleştirldi. Safra kesesi ameliyatı sonrası safra kaçağı olan hastalara da ERCP ile ES ve koledoğa plastik stent yerleştirilmesi işlemi yapılmıştı. Safra yolu stenozu olan hastalara ERCP işleminde çekilen kolanjiografide görülen dar segmenti geçecek şekilde ES sonrası plastik stent yerleştirilmesi yapılmıştı. Safra yolu tıkanılığı ile gelen 499 hastanın 63 tanesi akut biliyer pankreatit, 38'i akut kolanjit tanısıyla gelmişti. 


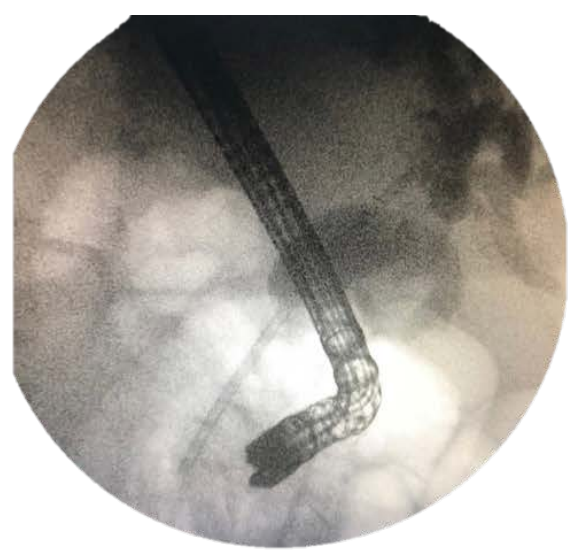

a

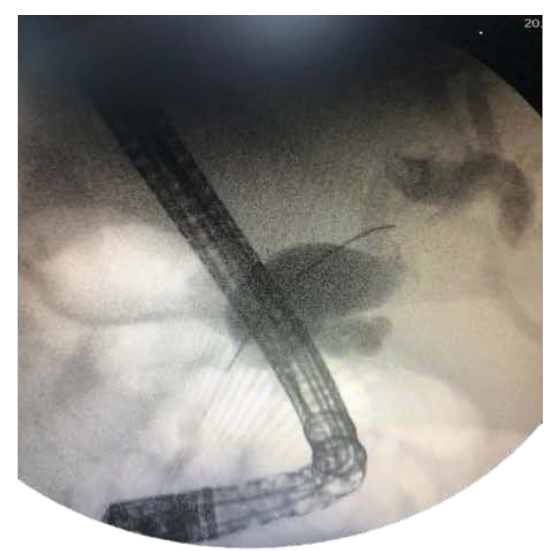

b
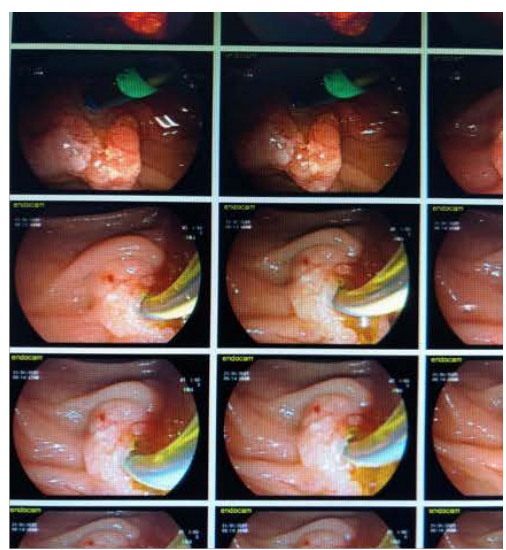

C

Şekil 1. a: Pankreas başı tümörü,koledok distalinde segmental bası bulgusu

b: Koledoktaki segmental darlığı içine alacak şekilde plastik stent yerleştirlmesi

c: Stent yerleştirildikten sonra safra akışı sağlandı

Ortalama ERCP işlem süresi 37 dakika (20-90 dk) idi. Çalışmamızda başarılı kanulasyon oranı \% 92 idi. ERCP esnasında ve post-ERCP dönemde komplikasyonlar $95(\% 18,5)$ vakada görülmüştü. Bunların 56'sı $(\% 10,9)$ post ERCP amilazemi, 24'ü $(\% 4,6)$ post ERCP pankreatit (PEP), 5’i $(\% 0,9)$ kanama, 1'i $(\% 0,1)$ koledokta taş-basket sıkışması olarak raporlanmıştı. Komplikasyonlardan taş-basket sıkışması gelișen hasta aynı seansta cerrahi müdahale ile tedavi

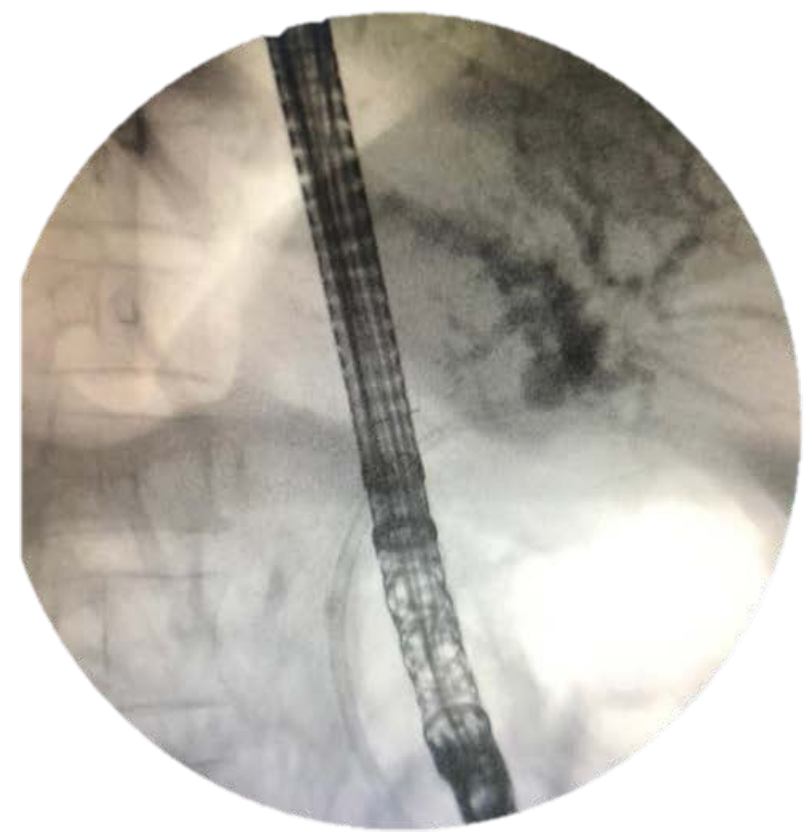

a edilmişti. Koledoktaki taş ve sıkışan basket kateter çıkarılmıştı. Kanamalar işlem esnasında sfinkterotomi sonucu gelişti. Bu vakaların transfüzyon ihtiyacı olmadı, işlem esnasında adrenalin enjeksiyonu ve balon kateter ile baskılanarak kontrol altına alındı. Geç dönemde kanama olmadı. Post ERCP Pankreatit (PEP) gelişen hastaların tümünün kliniği hafif seyretmiş ve hastaların hiçbirinde şiddetli pankreatit veya ölüm gelişmemişti. Ortalama üç günlük medikal tedavi ile iyileşme görülmüştü.

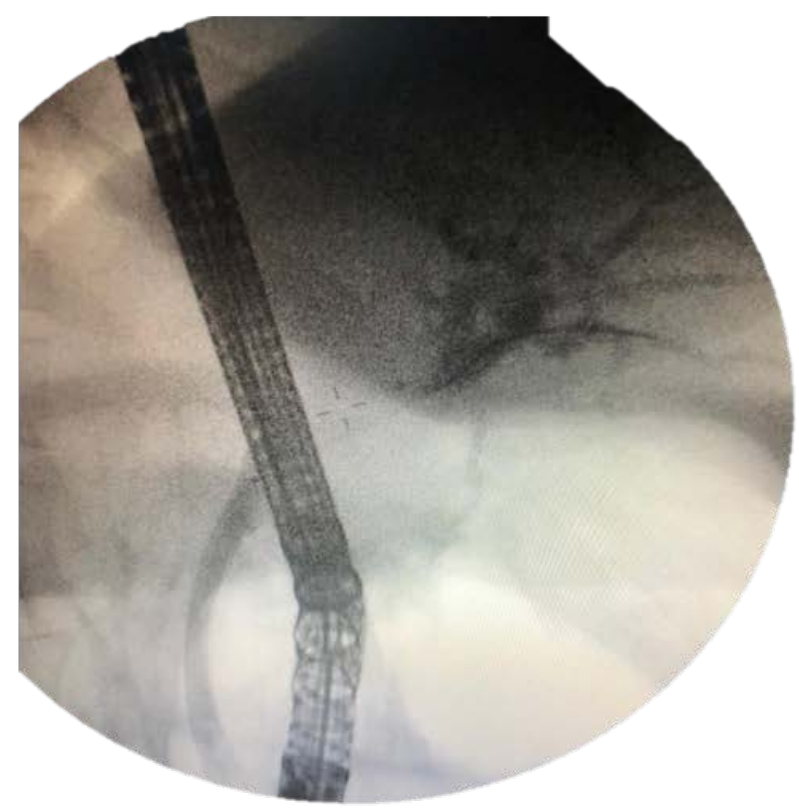

b

Şekil 2. a: Kolanjiografide koledok üst segmentte kolanjiokarsinom bulgusu

b: Koledok üst segmentteki kolanjiokarsinoma bağlı darlığı içine alacak şekilde plastik setent yerleştirlmesi 


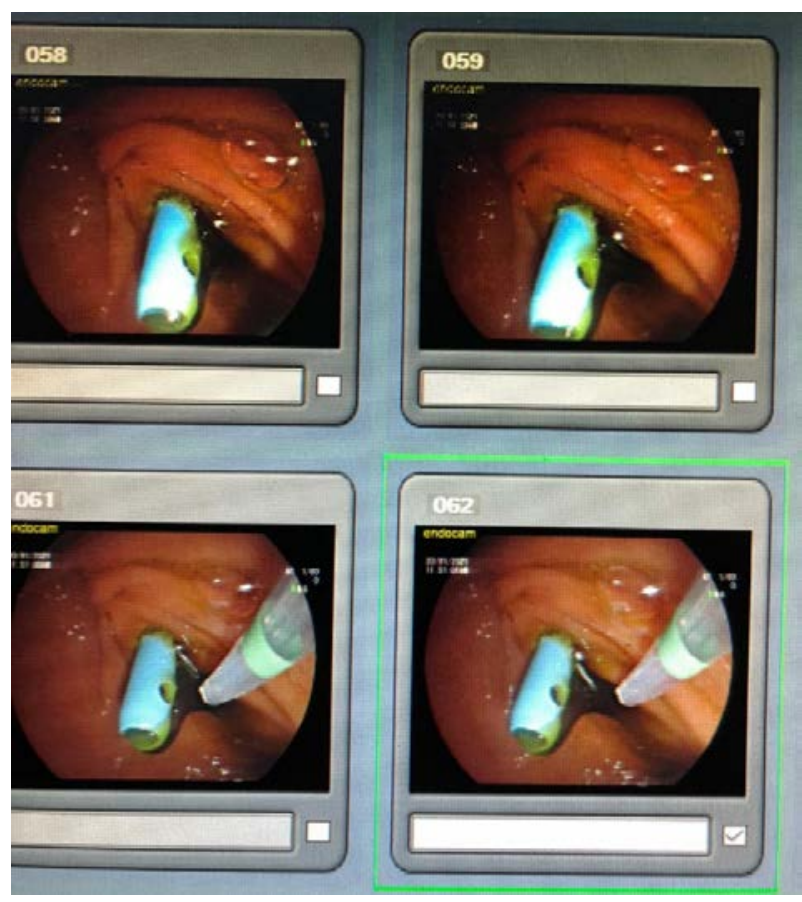

Şekil 3. Papil tümöründen biyopsi alınması

ERCP sonra amilazemi gelişen hastalarda tedaviye gerek olmamıştı ve ortalama 1 gün sonra taburcu edilmişlerdi. PEP $24(\% 4,6)$ vakada, post-ERCP hiperamilazemi 56 $(\% 10,9)$ vakada gözlenmişti. PEP gelişen $24(\% 4,6)$ vakanın yaş ortalaması PEP gelişmeyen vakalarla karşılaştırıldığında istatistiksel olarak anlamlı olmasa da daha küçüktü $(61,3 / 63,5$ yıl). PEP gelişenlerin 20'si $(\% 83,3)$ kadın, 4'ü $(\% 16,6)$ erkekti. Yaş dağılımları ve PEP gelişimi arasında anlamlı bir fark yoktu. PEP gelişen vakaların $21^{\prime}$ inde $(\% 87,5)$ koledokolitiazis ve kolestatik enzim artışı, 2'sinde $(\% 8,3)$ malignite, 1'inde $(\% 4,1)$ karaciğer kist hidatik ameliyatı sonrası safra kaçağı vardı. Bu vakaların 19'una $(\% 79,1)$ sfinkterotomive taş ekstraksiyonu yapılmıştı, $5^{\prime}$ ine $(\% 20,8)$ plastik stent yerleştirlmişti. PEP vakalarının tümüne standart sfinkterotomi yapılmıştı. Bu hasta serisinde ERCP sonrası $20(\% 3,8)$ hastada kolanjit görüldü. Bu hasta grubunda intraoperatif mortalite olmadı.

\section{Tartışma}

ERCP günümüzde safra yolları ve pankreato-biliyer tanı ve tedavide çok değerli bir konuma gelmiştir. ES ve stent uygulamaları ile kolesistektomi sonrası remnant koledok taşları, postoperatif safra yolu yaralanmaları, safra kaçağı, safra kanalı darlıkları gibi safra yolları sorunlarında oldukça faydalıdır (2).

ERCP ve MRCP nin koledokolityazis tanısı için karşılaştırılabilir hassasiyet ve özgüllüğü mevcuttur (5). Yapılan bir çalışmada MRCP'nin tüm safra yolları patolojilerinin değerlendirilmesinde duyarlılık, özgüllük, pozitif ve negatif prediktif değerleri sırasıyla, \%85.0, \%50.0, \%89.4 ve \%40.0 idi (6). Yüksek yumuşak doku kontrast çözünürlüğü ve periferik safra kanalı tutulumunun etkin biçimde değerlendirile- bilmesi MR görüntülemenin başlıca avantajlarıdır. Kontrast verilmeden yapılması, yan etkisinin olmaması, ucuz olması, kısa sürede yapılması ve yüksek doğrulukta sonuçlar vermesi nedeniyle MRCP safra yolları ve pankreatik kanal değerlendirilmesinde ilk başvurulması gereken tanı yöntemidir (7). Bizim kliniğimizde de tanıda görünütüleme yöntemlerinden karın ultrasonografisi ve MRCP mutlaka kullanılmıştı. Bazı vakalarda tanıyı kesinleştirmek için kontrastlı karın bilgisayarlı tomografisi (BT) çekildi.

Semptomatik safra taşı olanların \%8-18'inde koledokolitiazis oluşabilir (8). Literatürde ERCP ile koledok taşlarının çıkarılmasında başarı oranı \%80-97 arasındadır $(9,10)$. ÇaIışmamızda koledok taşı tanısıyla ERCP işlemine alınan 42 hastaya kanülasyon yapılamamıştı ve koledok taşı çıkarmadaki başarı oranı \%91,8' di.

Tablo 1. ERCP endikasyonları

\begin{tabular}{|l|c|}
\hline Endikasyon & $\mathbf{n}(\%)$ \\
\hline Koledok taşı & $452(\% 88,1)$ \\
\hline Papil tümörü & $10(\% 1,9)$ \\
\hline Pankreas tümörü & $15(\% 2,9)$ \\
\hline Koledok tümörü & $11(\% 2,1)$ \\
\hline Safra kaçağı & $10(\% 1,9)$ \\
\hline Safra kanalı stenozu & $4(\% 0,7)$ \\
\hline ODS & $10(\% 1,9)$ \\
\hline
\end{tabular}

ERCP: Endoskopik Retrograt Kolanjiyopankreatografi

ODS: Oddi Sfinkter Disfonksiyonu

MRCP'de safra kanalı taşları açısal konturlu, multipl dolum defektleri şeklinde görülür (11). Çalışmamızda koledok taşı olan hastalara yapılan MRCP görüntülemesi dolum defektleri şeklinde raporlanmıştı. Sadece $16(\% 3,5)$ hastada MRCP de taş raporlanmamıştı. Bu hastalara klinik ve laboratuvar sonuçlarına göre yapılan ERCP de taş ekstrakte edildi.

Benign biliyer striktürlerinin en yaygın sebebi (\%80-90) önceden geçirilmiş hepatobiliyer cerrahidir $(12,13)$. Çalışmamıda 4 hastada safra kesesi ameliyatı sonrası koledokta segmental daralma vardı. ERCP öncesi çekilen MRCP ile segmental koledok darlıkları ve distaldeki kollaps 4 hastada da gösterilmişti.

ODS; Oddi sfinkterinin organik veya fonksiyonel anormalliğine bağlı ortaya çıkan biliyer ve/veya pankreatik obstrüksiyonda görülen tablodur. Klinik olarak şüpheli oddi sfinkter disfonksiyonu (ODS) olan hastalarda, MR kolanjiopankreatografi bulguları oddi sfinkterinde fokal darlık, distal ana safra kanalında gittikçe incelen daralma ve dilate ekstrahepatik safra kanal (genellikle $>12 \mathrm{~mm}$ ) ile birlikte intrahepatik safra kanallarında ve ana pankreatik kanalda hafif darlık olması ya da olmaması ile ortaya çıkar (14). Çalışmamızda klinik bulgular ve laboratuvar değerlerinde ODS şüphesi olan hastalara yapılan MRCP incelemesinde koledok distal uçta incelerek sonlanma ve koledokta genişleme olduğu belirtilmişti. ODS olan hastalara sadece ES yapıldı ve yeterli oldu. Bu hastalarda teknik şartlar nedeniyle monometri uygulanamadıysa da biyokimyasal anormalliklerin yanı sıra klinik semptomlar vardı ve ERCP sonrası hastalarda klinik ve laboratuvar olarak düzelme sağlandı. 
Tablo 2. ERCP komplikasyonları

\begin{tabular}{|l|c|}
\hline Komplikasyonlar & $\mathbf{n ( \% )}$ \\
\hline Serum amilaz yüksekliği & $56(\% 10,9)$ \\
\hline Akut pankreatit & $24(\% 4,8)$ \\
\hline Kolanjit & $20(\% 3,8)$ \\
\hline Kanama & $5(\% 0,9)$ \\
\hline Perforasyon & 0 \\
\hline Koledokta taş basket sıkışması & $1(\% 0,1)$ \\
\hline
\end{tabular}

ERCP:Endoskopik Retrograt Kolanjiyopankreatografi

ERCP yaklaşık 20 yıldan fazla bir zamandır pankreatik ve safra yolu hastalıklarının tanısında ve günümüzde artık neredeyse sadece tedavisinde kullanılmaktadır. Sarılıklı hastada kolanjiyografi; ERCP veya PTK ile elde edilebilir. Genelde ERCP tercih edilir çünkü daha çok tanısal bilgi sağlar (safra yoluyla beraber papilla ve pankreasta görüntülenebilir) ve daha geniş tedavi spektrumu mevcuttur. Malign tıkanıklığı olan hastaların sadece \%20'si ameliyat edilebilmektedir. Bunların da yarısına rezeksiyon, diğer yarısına palyatif by-pass yapılmaktadır (15). ERCP, safra yolları ve pankreas malignitelerinin tanı ve palyatif tedavisinde de değerli bilgiler sunar. Safra yollarının obstruktif malignitelerinde cerrahi tedavi ancak yarısında uygulanabilir ve bu hastaların \% 20'sinde küratif cerrahi yapılabilir. Yapılan çalışmalarda inoperable hastaların endoskopik palyatif tedavisinde ERCP \%80-90 başarı oranına sahiptir (16). Bu yüzden ERCP ile stendleme tercih edilir.

Kontrastlı manyetik rezonans ile MRCP yüksek yumuşak doku rezolusyonu ve periferal duktal tutulumu gösterme kapasitesi nedeniyle kolanjiokarsinom değerlendirilmesinde özellikle faydalıdır $(17,18)$.

Adenokarsinom erişkinlerde görülen en sık pankreas malign neoplazmıdır. Tümörlerin \%70'i baş, boyun ve unsinat proçeste görülür ve genellikle ana safra kanalının intrapankreatik bölümünde oluşan daralma nedeniyle obstruktif sarılıkla ortaya çıkar (19). MRCP'de ana safra kanalı ve ana pankreatik kanalda kitlenin olduğu düzeyde ani sonlanma ve tıkanmanın yukarısında duktal genişleme görülür $(20,21)$.

Çalışmamızda malign biliyer darlık sebebi olan pankreas başı tümörü tanısı olan hastalarda MRCP de kitlenin olduğu koledok segmentinde belirgin daralma gözlenmişti. Kolanjiokarsinom tanılı hastalarda tümörün olduğu koledok segmentinde düzensizlik ve daralma raporlanmıştı. Papilla tümörü de $\mathrm{MRCP}$ 'de distal koledokta papilla düzeyinde asimetrik daralma ve üst kısımda genişleme görülmüştü. Çalışmamızda ERCP yapılan hastalarda işlem öncesi çekilen MRCP görüntülemelerinin raporları ERCP işlemindeki tanılarla uyumlu idi.

Çalışmamızda tıkanma sarılığıyla gelen ve ERCP işlemiyle stent yerleştirilen 15 hastada pankreas başı tümörü, 11 hastada safra yolu tümörü vardı. Bu hastalarda işlem sonrası bilirubin değerleri ve karaciğer fonksiyon değerleri normale yakın değerlere kadar düştü ve klinik olarak düzelme gözlendi. 10 hastada papilla tümörü teşhisi konulmuştu ve bu hastalar tıkanma sarılığı, karın ağrısı ve ılımlı anemi ile gelmişti. Bu hastalara da koledok stenti yerleştirildi.

Akut pankreatitte ERCP'nin tanısal değeri literatürde \%3879 olarak bildirilmiştir (22). Eğer bu nedenle ERCP yapılacaksa biliyer ve/ veya pankreatik sfinkterotomi gereklidir. Yüksek riskli hastalarda ise pankreas kanalına stent yerleştirilebilir veya rektal indometazin kullanılabilir. İdiopatik akut rekürren pankreatitte eğer biliyer taş ya da çamuru gösterilemezse, EUS ve/veya MRCP bulguları normal ise Oddi sfinter manometrisi ile birlikte ERCP düşünülebilir.

Akut biliyer pankreatitte (ABP) beraberinde akut kolanjit tablosunun olup olmaması ERCP kararı vermede önemlidir. Akut kolanjit varlığında antibiyotik tedavisi ve biliyer dekompresyon sonrasında mortalite \%100'den \%9-40'lara kadar gerilemiştir. Her hastaya acil girişimde bulunmak uygun değildir. ABP'de akut kolanjit birlikteliği acil ERCP gereksinimi doğuran bir durumdur. Akut kolanjitte biliyer pankreatitlerde ERCP ile ES ve/veya stenteleme yaygın olarak kullanılmaktadır $(4,23)$. Bizim çalışmamızda safra yolu tıkanılığıyla birlikte 63 hastada akut pankreatit, 38 hastada akut kolanjit mevcuttu. Akut biliyer pankreatitle gelen hastaların amilaz, lipaz değerleri yüksekti ve batın USG ve batın BT görüntülemelerinde pankreas etrafında ödem ve karın içerisinde serbest sıvı raporlanmıştı. Bu hastalara öncelikle medikal tedavi uygulandıktan sonra ortalama 5.günde ERCP uygulandı.

Kliniğimize akut kolanjit tanısıyla kabul edilen hastalarda karaciğer fonksiyon testleri yüksekti ve lökositoz mevcuttu. CRP değerleri yüksekti. Karın USG ve MRCP görüntülemelerinde koledokta genişleme ve distal koledokta dolum defektleri raporlanmıştı. Akut kolanjitli hastalara öncelikle iv antibiyotik ve sıvı replasmanı tedavisi uygulanmıştı ve ortalama 5.günde ERCP uygulandı. Bu hastalara $E R C P^{\prime}$ de ES yapıldı ve koledok taşı olanlara taş ekstraksiyonu ve/veya stentleme uygulandı.

Karaciğer kist hidatik ameliyatını takiben hastaların \%1416 'sında biliyer komplikasyon meydana gelir. Bu komplikasyonlar ya erken dönemde görülen biliyer fistül ve tıkanma sarılığı veya geç dönemde ortaya çıkan benign biliyer darlık şeklindedir. Endoskopik tedavi sfinkterotomi, safra kanalındaki debrislerin temizlenmesi ve endoskopik stent veya nasobiliyer drenajı içerir. Bu çalışmada 5 hastaya karaciğer kist hidatik ameliyatı sonrası safra kaçağı nedeniyle ERCP yapılmıştı. Hastaların 4'ü kadın 1'i erkekti.

Hastaların ameliyat sonrası takiplerinde ortalama $700 \mathrm{cc}$ ve üzeri devam eden safra kaçağı olmuştu. Safra drenajının devam etmesi ve yüksek debili olması nedeniyle ERCP yapılmıştı. İşlemde ES yapıldı. Safra kanallarının duodenuma drenajı sağlandı ve koledoğa plastik stent yerleştirlildi. Dört hastada safra drenajı giderek azaldı ve ortalama 10 gün içinde drenleriyle birlikte taburcu edilmişlerdi. Bir hastanın safra drenajı 1 ay devam etti, drenajı azalan hasta dreniyle birlikte taburcu edildi.

Postoperatif safra kaçağı tespit edilen bir hasta öncelikle endoskopik olarak tedavi edilmeye çalışılmalıdır. Sfinkterotomi ve nazobiliyer drenaj/stentleme intraduktal basıncı 
azaltarak safranın kaçak olan bölgeden uzaklaştırılarak duodenuma rahatça akmasını sağlar. Çalışmamızda laparaskopik kolesistektomi ameliyatı sonrası safra kaçağı olan 3 hastaya ERCP yapıldı. Ameliyat sonrası safra kaçağı olan hastalar ortalama 3 gün içinde ERCP ye alınarak hepsine ES yapıldı ve $10 \mathrm{fr}(12 \mathrm{~cm})$ plastik stent yerleştirildi. Hastaların 1 'inde koledoktan taş ekstraksiyonu da yapıldı. Bu hastalar ERCP sonrası drenlerinden safra sızıntısı kesildikten sonra, ortalama 5 gün içinde taburcu edildi.

ERCP'de kanulasyon başarı oranı \%79,6-\%94,6 arasında değişmektedir $(4,23)$. Çalışmamızda kanulasyon başarı oranı \%92'dir.

ERCP işlemine bağı kanama, kolanjit, pankreatit, duedenal perforasyon, gram negatif sepsis gibi komplikasyonlar \%23 oranında görülürken mortalite $\% 0,1-1,5$ arasındadır $(23,24)$. En sık bakteriyemiye sebep olan girişim özellikle safra yollarında obstrüksiyon bulunan vakalarda yapılan ERCP işlemidir. Bu yüzden uyguladığımız ERCP işlemlerinden önce profilaktik antibiyotik uygulandı. Bu hasta serisinde ERCP sonrası 20 hastamızda kolanjit görüldü. Bu hastalardan 1'i ERCP sonrası kolanjite bağlı sepsis nedeniyle hayatını kaybetti. Bu hasta 38 yaşında kadındı. Hikayesinde sakrokoksigeal bölgede periferik sinir kaynaklı inoperabl tümör teşhisi vardı.

Post-ERCP pankreatit en sık ERCP komplikasyonudur, toplam insidansı \%3-10 olarak bildirilmiştir (25). Vakaların çoğu hafif pankreatit olup mortalite oranı \% 0,7'dir. Bu hasta serisinde $24(\% 4,6)$ hastada PEP görülmüştür. PEP riski genç yaş (55 yaş altı) ve kadın cinsiyette artmaktadır. Literatür ile uyumlu olarak çalışmamızda PEP kadınlarda daha sık ve daha genç yaşta (61,3 yıl'a karşı 63,5 yıl) görülmekle birlikte oran olarak anlamlı farklılık yoktu. ERCP'nin kaçıncı ERCP işlemi olduğu ve PEP gelişimi açısından karşılaştırıldığında PEP gelişen vakaların 22'si $(\% 91,6)$ birinci ERCP işlemi uygulanan, 2'si $(\% 8,3)$ ikinci ve üstü tekrarlayan ERCP işlemi uygulananlar arasında gelişmiş idi. PEP gelişimi ilk ERCP yapılanlarda anlamlı olarak daha sık gözlenmektedir.

Tanısal ERCP sonrası kanama nadiren görülür, kanamanın ana sebebi sfinkterotomidir. Bu şekilde kanama oranı literatürde $\% 0,3-2$ olarak bildirilmiştir $(26,27)$. Bizim serimizde 5 hastada $(\% 0,9)$ sfinkterotomi sırasında kanama olmuştur. Balon baskısıyla ve adrenalin enjeksiyonuyla kanamalar işlem esanasında durduruldu. Geç dönemde kanama görülmedi. İşlem sonrası kan transfüzyonu ihtiyacı olmadı. Delinme; ERCP işlemi sırasında lüminal perforasyon olursa intraperitoneal, sfinterotomi sırasında intarmural perforasyon olursa retroperitoneal kaçaklara neden olur. Üçüncü tip perforasyon ise kılavuz tel ya da diğer ektramural olarak lümen dışına çıkışı şeklinde gerçekleşir. Duodenal perforasyon sıklığı \%0,08-0,6 olarak bildirilmiştir (28). Perforasyon gecikmeden tanınmalı ve tedavi edilmelidir aksi takdirde sepsis ve çoklu organ yetmezliği ile sonuçlanabilir. Bu durumda mortalite \%8-23 olarak bildirilmiştir (29). Perforasyonun en önemli nedeni kontrolsüz kesi ve sfinkteretomi telinin büyük bölümünün papilla içinde tutularak kesi yapılmasıdır. Kesi açısı iyi ayarlanmalı ve sfinkterotom içinden geçen kılavuz tel koledok içinde olmalıdır. Bizim serimizde ERCP işleminde sfinkterotomiye bağlı perforasyon olmamıştır.

Literatürde bildirilen periampuller divertikül varlığı \%6-20 arasındadır (24). Periampuller divertikülü olan hastalarda koledok kanülasyonu daha zordur ve özel bir beceri gerektirir. Ayrıca bu divertikülün varlığı ERCP sonrası koledokta taş kalma riskini artırmaktadır. Bizim hastalarımızın $48^{\prime}$ inde $(\% 9,3)$ periampuller divertikül vardı. Periampuller divertikül olan hastalarda komplikasyon oranı diğer hastalardan farklı değildi.

ERCP nin geç dönem komplikasyonları içinde 5 yıldan sonra \%5-10 restenoz ve kolesistit vardır. Yeterli bir sfinkterotomi sonrası papiller stenoz klinik olarak nadir görülen bir durumdur. Bu çalışma süresi geç dönem komplikasyonları değerlendirecek kadar uzun olmadığından bu konuda bilgi sunulmamıştır.

\section{Sonuç}

ERCP uzun süreli bir konvansiyonel endoskopi deneyimi ve uzun süreli bir eğitim gerektirmektedir. Ayrıca ERCP sonrası oluşabilecek komplikasyonların hemen tamamı (pankreatit, pankreatik abse, perforasyon ve kanama gibi), genel cerrahi uygulamaları ile ilişkilidir ve genel cerrahi kliniklerinde takip/tedavi edilmektedir. ERCP ile ciddi komplikasyonlar görülebilmesine rağmen uygun endikasyonda ERCP yapılması ve oluşan komplikasyonların erken tanınmasının morbidite ve mortalitenin önlenmesinde en önemli kural olduğu kanaatindeyiz.

ERCP etkin olduğu kadar bünyesinde perforasyon, sepsis ve mortalite gibi çok ciddi komplikasyonları barındırdığından endoskopistin uygulamanın endikasyonunu doğru belirlemesi, potansiyel komplikasyonlarını bilip tedavisini yönetmesi, komplikasyon yaratacak ve gereksiz uygulamalardan kaçınması gerektiği kanaatindeyiz.

Etik onam: Çalışmanın etik kurul onamı Harran Üniversitesi klinik araştırmalar etik kurulundan (15.03.2021-HRU 21.06.10) alınmıştır.

\section{Yazar Katkıları:}

Konsept: E.T.U.

Literatür Tarama: M.T.

Tasarım: M.T.

Veri toplama: E.T.U.

Analiz ve yorum: M.T.

Makale yazımı: E.T.U.; M.T.

Eleştirel incelenmesi: M.T.

Çıkar Çatışması: Herhangi bir çıkar çatışmamız bulunmamaktadir.

Finansal Destek: Araştırma kapsamında herhangi bir kurum ya da kuruluştan finansal destek sağlanmamıştır. 


\section{Kaynaklar}

1. Galip E. Endoscopic Retrograde Cholangıopancreatography In Bilıe Duct Disorders. Turkiye Klinikleri J Int Med Sci. 2007;3(51):12-6

2. Adler DG, Baron TH, Davila RE, et al. Standards of Practice Committee of American Society for Gastrointestinal Endoscopy. ASGE guideline: the role of ERCP in diseases of the biliary tract and the pancreas. Gastrointest Endosc 2005; 62: 1-8.

3. Masci E, Toti G, Mariani A, et al. Complications of diagnostic and therapeutic ERCP: a prospective multicenter study. Am J Gastroenterol 2001; 96: 417-23

4. Kondo $S$, Isayama $H$, Akahane $M$, et al. Detection of common bile ductstones: comparison between endoscopic ultrasonography, magnetic resonanc cholangiography, and helical-computed-tomographic cholangiography.Eur J Radiol 2005;54:271-5.

5. Cohen, S., Bacon, B.R., Berlin, J.A. et al. National Institutes of Health State-of-the-Science Conference Statement: ERCP for diagnosis and therapy, January $14-16,2002$. Gastrointest Endosc 2002; 56: 803 - 9

6. Değerli ZB, YıImaz Ö, Gökharman FD, Koşar U. Sakarya Tıp ergisi.Pankreatikobilier Patolojilerde Manyetik Rezonans Kolanjiopankreatografi ile Endoskopik Retrograd Kolanjiopankreatografinin Karşılaştırılması,2012;2(4):174-180

7. Ahmad Ci,Serter A. Magnetic Resonance CholangiographyTurkiye Klinikleri J Radiol-Special Topics. 2013;6(3):8-12.

8. Ko CW, Lee SP. Epidemiology and natural history of common bile duct stones and prediction of disease. Gastrointest Endosc 2002; 56 (6 suppl):S165-9.

9. Sakai $Y, T$ suyuguchi $T$, Ishihara $T$, et al. The use fulness of endoscopic transpapillary procedure inpost-cholecystectomy bile duct stricture and postcholecystectomy bile leakage. Hepatogastroenterology 2009; 56: 978-83.

10. Aksoz K, Unsal B, Yoruk G, et al. Endoscopic sphincterotomy alone in the management of low-grade biliary leaks due to cholecystectomy. DigEndosc2009; 21: 158-61.

11. Gallix BP, Regent $D$, Bruel JM. Use of magnetic resonance cholangiography in the diagnosis of choledocholithiazis. Abdom Imaging 2001; 26: 21-7

12. Moser AJ. Benign biliary strictures. Curr Treat Options Gastroenterol 2001; 4: 377-87.

13. Jablonska $B$, Lampe $P$. latrogenic bile duct injuries: etiology, diagnosis and management. World J Gatroenterol 2009; 15: 4097-104.

14. Pereira SP, Gillams A, Sgouros SN, Webster GJ, Hatfield AR. Prospective comparison of secretin-stimulated magnetic resonance cholangiopancreatography with manometry in the diagnosis of sphincter of Oddi dysfunction types II and III. Gut. 2007;56(6):809-813. doi:10.1136/gut.2006.099267

15. Cotton, P.B. ERCP: risks, prevention, and management. In: Advanced Digestive Endoscopy Series: ERCP Section. Cotton, P.B.; Ed Charleston, S.C., USA: The Digestive Disease Center at the Medical University of South Carolina (MUSC). Edited by: Peter, B. Cotton and Joseph, W.C. Leung. Blackwell Pub, 2005; 13: $339-404$

16. Baron TH, Kozarek RA. Preoperative biliary stents in pancreatic cancer - Proceed with caution. N Engl J Med 2010; 362: 170-2.

17. Sainani NI, Catalano OA, Holalkere NS, Zhu AX,Hahn PF, Sahani DV. Cholangiocarcinoma: current and novel imaging techniques. Radiographics 2008;28: 1263-87.
18. Slattery JM, Sahani DV. What is the current state-of- theart imaging for detection and staging of cholan- giocarcinoma. Oncologist 2006; 11: 913-22.

19. Chhibber S, Sharma AK, Kumar N, Ghumman S Puri SK. Pancreatic tumors: prospective evaluation using MR imaging with MR cholangiography and MR angiography. Indian J Radiol Imaging 2006; 16:515-21.

20. Miller FH, Rini NJ, Keppke AL. MRI of adeno- carcinoma of the pancreas. AJR Am J Roentgenol 2006;187: W365-74.

21. Vachiranubhap B, Kim YH, Balci NC, Semelka RC.Magnetic resonance imaging of adenocarcinoma of the pancreas. Top Magn Reson Imaging 2009; 20:3-9.

22. Cotton PB, Garrow DA, Gallagher J, Romagnuolo J. Risk factorsfor complications after ERCP: a multivariateanalysis of 11,497 procedures over 12 years. Gastrointest Endosc 2009; 70: 80-8.

23. Adler DG, Baron TH, Davila RE, et al. Standards of PracticeCommittee of American Society for Gastrointestinal Endoscopy. ASGE guideline: the role of ERCP in diseases of the biliary tract and the pancreas. GastrointestEndosc 2005; 62: 1-8.

24. Yamaner S, Bilsel $Y$, Bulut $T$, Bugra D, Buyukuncu $Y$, Akyuz A. Endoscopic Diagnosis and management of complications following surgery for gallstones. Surg Endosc.2002; 16: 1685-90.

25. Freeman ML, DiSario JA, Nelson DB, Fennerty MB, Lee JG, Bjorkman DJ, Overby CS, Aas J, Ryan ME, Bochna GS, Shaw MJ, Snady HW, Erickson RV, Moore JP, Roel JP. Risk factors for post-ERCP pancreatitis: a prospective, multicenter study. Gastrointest Endosc. 2001 Oct;54(4):425-34. doi: 10.1067/mge.2001.117550. PMID: 11577302.

26. Cotton PB, Garrow DA, Gallagher J, Romagnuolo J. Risk factors for complications after ERCP: a multivariate analysis of 11,497 procedures over 12 years. Gastrointest Endosc 2009; 70: 80-8.2001;54:425-34.

27. Rustagi $T$, Jamidar PA. Endoscopic retrograde cholangiopancreatography-related adverse events: general overview. Gastrointest Endosc Clin N Am. 2015 Jan;25(1):97106. doi: 10.1016/j.giec.2014.09.005. PMID: 25442961.

28. Silviera ML, Seamon MJ, Porshinsky $B$, Prosciak MP, Doraiswamy VA, Wang CF, et al. Complications related to endoscopic retrograde cholangiopancreatography: a comprehensive clinical review. J Gastrointestin Liver Dis 2009; 18: 73-82.

29. Machado NO. Management of duodenal perforation postendoscopic retrograde cholangiopancreatography. When and whom to operate and what factors determine the outcome? A review article. JOP 2012; 13: 18-25 